\title{
Clinical, haematological and biochemical findings in tigers infected by Leishmania infantum
}

\author{
Maria Alfonsa Cavalera ${ }^{1}$, Roberta latta', Pietro Laricchiuta², Giuseppe Passantino ${ }^{1}$, Francesca Abramo³, \\ Jairo Alfonso Mendoza-Roldan', Domenico Otranto ${ }^{1,4}$ and Andrea Zatelli ${ }^{1 *}$ (D)
}

\begin{abstract}
Background: A large number of animal species are susceptible to Leishmania infantum (Kinetoplastida, Trypanosomatidae) in endemic areas, including domestic and wild felids such as tigers (Panthera tigris). Knowledge on the infection of this endangered species is still at its infancy, and therefore this study aims to identify clinical presentation and clinicopathological findings of tigers naturally infected by $L$. infantum.

Results: Tigers either L. infantum-positive (group A) or -negative (group B) were apparently healthy or presented visceral leishmaniasis unrelated conditions, except for one animal in which a large non-healing cutaneous lesion was observed. However, histological exam and immunohistochemistry carried out on the lesion excluded the presence of $L$. infantum amastigotes. Biochemical analysis showed that the average concentration of total proteins, globulins and haptoglobin were significantly higher $(p<0.01, p=0.01$ and $p=0.02$, respectively), while the albumin/globulin ratio significantly lower $(p=0.05)$ in group A compared with group B. The biochemical alterations were partially confirmed by the serum protein electrophoresis results revealing a significant increase in the total protein value $(p=0.01)$ and hypergammaglobulinemia $(p=0.03)$ but an unmodified albumin/globulin ratio in group A.
\end{abstract}

Conclusions: In this study tigers infected by L. infantum have shown to be mainly asymptomatic. The absence of clinical signs may lead veterinarians to overlook leishmaniasis in animals kept in captivity. Therefore, diagnostic and screening tests as serology should be part of routinely surveillance programs to be performed on tigers in zoological gardens located in endemic areas. Though only few protein-related laboratory abnormalities were recorded in infected animals, they could provide diagnostic clues for a first suspicion of $L$. infantum infection in tigers. Indeed, considering the high risk of zoonotic transmission in heavily frequented environment as zoos, a prompt diagnosis of $L$. infantum infection is of pivotal importance.

Keywords: Tiger, Leishmaniasis, Symptomatology, Laboratory abnormalities, Dysproteinemia

\section{Background}

Leishmania infantum (Kinetoplastida, Trypanosomatidae) has been recognised as the main causative agent of canine leishmaniasis (CanL) [1]. This zoonotic sand fly-borne disease is one of the world's most important neglected illnesses [2], though it is potentially fatal to humans if left

\footnotetext{
* Correspondence: andrea.zatelli@uniba.it

'Department of Veterinary Medicine, University of Bari, 70010 Valenzano, Italy Full list of author information is available at the end of the article
}

untreated [3]. Dogs are the main peridomestic reservoir host of the protozoa [4], developing a chronic and multisystemic infection that may potentially involve any organ [5]. Consequently, CanL is characterized by a wide variety of non-specific clinical presentations ranging from asymptomatic infection to a severe fatal clinical disease, mainly depending on the host's Th1/Th2 immune responsiveness $[6,7]$. The most common clinical manifestations of CanL

C C The Author(s). 2020 Open Access This article is licensed under a Creative Commons Attribution 4.0 International License, which permits use, sharing, adaptation, distribution and reproduction in any medium or format, as long as you give appropriate credit to the original author(s) and the source, provide a link to the Creative Commons licence, and indicate if changes were made. The images or other third party material in this article are included in the article's Creative Commons licence, unless indicated otherwise in a credit line to the material. If material is not included in the article's Creative Commons licence and your intended use is not permitted by statutory regulation or exceeds the permitted use, you will need to obtain permission directly from the copyright holder. To view a copy of this licence, visit http://creativecommons.org/licenses/by/4.0/. The Creative Commons Public Domain Dedication waiver (http://creativecommons.org/publicdomain/zero/1.0/) applies to the data made available in this article, unless otherwise stated in a credit line to the data. 
due to $L$. infantum are skin lesions, lymphadenomegaly and weight loss $[7,8]$.

In endemic areas, $L$. infantum is maintained by several mammal species in nature [9] and the role of wildlife species (e.g., red fox, golden jackal, gray wolf, hare, black rat) has been suggested in a series of studies [10,11]. After being long regarded as resistant, cats have gain the interest of the scientific community as hosts of $L$. infantum, mainly in endemic areas $[12,13]$. Clinical signs compatible with feline leishmaniasis (FeL) include lymphadenomegaly, splenomegaly, weight loss, anorexia, as well as cutaneous, mucocutaneous and ocular lesions [14]. However, the subclinical infection seems more common in endemic regions such as Mediterranean countries [14]. The complex pathogenesis and the broad spectrum of clinical manifestations of visceral leishmaniasis (VL) in domestic animals make its diagnosis still challenging [15]. Although the diagnosis of VL can be achieved by performing specific tests (i.e., serology, cytology, PCR, xenodiagnosis), laboratory abnormalities uncovered by routine haematology, clinical chemistry, or urinalysis may support the clinical suspicion of VL [15]. For example, in CanL, nonregenerative normocytic normochromic anemia, leukogram changes (i.e. neutrophilia), trombocytopenia and dysproteinemia (i.e., hyperproteinemia, hyperglobulinemia, hypoalbuminemia, inversion in the albumin/globulin ratio) represent typical laboratory findings $[1,15,16]$. Renal dysfunction may be revealed by clinical chemistry (renal azotemia) and urinalysis (decreased urine specific gravity and proteinuria). Serum protein electrophoresis (SPE) is commonly used to identify a polyclonal gammopathy that may also appear oligo-monoclonal, especially in dogs coinfected by other vector-borne pathogens $[1,15]$. Additionally, the increase of acute phase proteins (APP) and other markers of inflammation (i.e., C-reactive protein [CRP], serum amyloid A [SAA], haptoglobin [HPT], ferritin) have been frequently associated with CanL $[15,16]$.

In cats, scant information is available about laboratory abnormalities in L. infantum infected individuals as only the major body of literature is represented by case reports. Mild to severe normocytic normochromic nonregenerative anemia and hyperproteinemia with hypergammaglobulinemia are the main abnormalities reported $[17,18]$ followed by moderate to severe pancytopenia in association with aplastic bone marrow, particularly in FIV-positive cats. Unlike in dogs, hypoalbuminemia is only occasionally detected in FeL [17]. Recently, wild species of felids, including tigers (Panthera tigris), have been recognized as susceptible hosts to $L$. infantum in endemic areas $[19,20]$. Considering that knowledge of the infection of this endangered species [21] is still at its infancy, data on clinical picture in tigers infected by $L$. infantum are missing. Thus, the aim of this study was to identify clinical presentation and clinicopathological findings of tigers naturally infected with $L$. infantum.

\section{Results \\ Clinical findings}

Tigers (8 males and 12 females), individually identified by microchip, aged from 6 months to 11 years, weighed from 70 to $220 \mathrm{~kg}$ and showed a BCS $=3$ except for the tiger $4(\mathrm{BCS}=2)($ Table 1$)$. Animals from group A (i.e. $L$. infantum-positive animals) as well as those from group B (i.e $L$. infantum-negative animals) were apparently healthy or presented VL unrelated conditions, except for the tiger 1 in which a large $(10 \mathrm{~cm})$ non-healing cutaneous lesion was observed. After an incisional skin biopsy of the lesion, an histological exam has been performed revealing a chronic ulcerative dermatitis and vasculitis/perivasculitis with plasma cellular infiltrate. During the histological examination, no pathogens were detected. The absence of amastigotes was also confirmed by immunohistochemistry.

\section{Haematological and biochemical findings}

Mean and median values of complete blood count $(\mathrm{CBC})$ and biochemical parameters obtained from group $\mathrm{A}$ and $\mathrm{B}$ are statistically compared and reported in Tables 2 and 3, respectively. The SPE results are shown in Table 3. Data available on the Zoological Information Management System (ZIMS) from Species 360 (formerly the International Species Inventory System, ISIS) have been included, when available, as haematology and biochemistry reference values of the tigers (Tables 2,3). Biochemical analysis showed that the average concentration of total proteins, globulins and haptoglobin were significantly higher $(p<$ $0.001, p=0.01$ and $p=0.02$, respectively), while the albu$\mathrm{min} /$ globulin ratio significantly lower $(p=0.05)$ in group A compared with group B. Urine samples were collected from 12 (i.e. $n=6 L$. infantum-positive tigers and $n=6 L$. infantum-negative tigers) out of 20 animals. Mean and median values of urine specific gravity (USG) and urine protein/creatinine ratio (UP/C) detected in group A and B are reported in Table 3.

\section{Discussion}

This study represents the first identification of clinical presentation and clinicopathological findings in L. infantum naturally infected tigers. These animals have shown to be asymptomatic considering the clinical pictures usually detected in CanL and FeL [7, 8, 14]. Although data on the pathogenesis of $L$. infantum infection in tigers are missing, it can be supposed that progression to illness could be associated with increasing antibody titres as it occurs in CanL and, likely, in FeL [6, 14]. Indeed, out of 8 asymptomatic tigers positive at IFAT, 7 presented a low antibody titre (i.e., $n=3$ 1:40, $n=4$ 1:80). 
Table 1 Data on sex, age, body weight, body condition score (BCS), serological and molecular results for Leishmania infantum of the 9 and 11 tigers enrolled in group A (L. infantum-positive animals) and group B (L. infantum-negative animals)

\begin{tabular}{|c|c|c|c|c|c|c|c|c|}
\hline \multirow[t]{2}{*}{ Group } & \multirow{2}{*}{$\begin{array}{l}\text { Tiger } \\
\text { ID }\end{array}$} & \multirow{2}{*}{$\begin{array}{l}\text { Sex } \\
(\mathrm{M} / \mathrm{F})\end{array}$} & \multirow{2}{*}{$\begin{array}{l}\text { Age } \\
\text { (years) }\end{array}$} & \multirow{2}{*}{$\begin{array}{l}\text { Weight } \\
(\mathrm{kg})\end{array}$} & \multirow{2}{*}{$\begin{array}{l}\text { BCS } \\
(1-5)\end{array}$} & \multirow{2}{*}{$\begin{array}{l}\text { IFAT/ } \\
\text { Ab } \\
\text { titre }\end{array}$} & \multicolumn{2}{|l|}{ qPCR results } \\
\hline & & & & & & & Lymph node & Swab (conjuntival, oral, nasal) \\
\hline \multirow[t]{9}{*}{ A } & 1 & $\mathrm{~F}$ & 7 & 150 & 3 & $1: 160$ & pos & neg \\
\hline & 2 & M & 6 & 160 & 3 & $1: 80$ & $\mathrm{nt}$ & neg \\
\hline & 3 & M & 7 & 220 & 3 & $1: 80$ & neg & neg \\
\hline & 4 & M & 8 & 210 & 2 & $1: 80$ & $\mathrm{nt}$ & pos \\
\hline & 7 & $\mathrm{~F}$ & 2 & 135 & 3 & $1: 640$ & pos & pos \\
\hline & 9 & $\mathrm{~F}$ & 2 & 150 & 3 & $1: 40$ & pos & neg \\
\hline & 10 & M & 2 & 170 & 3 & $1: 40$ & pos & pos \\
\hline & 11 & $\mathrm{~F}$ & 8 & 190 & 3 & $1: 40$ & neg & neg \\
\hline & 17 & $F$ & 7 & 150 & 3 & 1:80 & neg & neg \\
\hline \multirow[t]{11}{*}{ B } & 5 & $M$ & 7 & 220 & 3 & neg & neg & neg \\
\hline & 6 & $F$ & 9 & 150 & 3 & neg & neg & neg \\
\hline & 8 & $M$ & 2 & 180 & 3 & neg & nt & neg \\
\hline & 12 & $M$ & 6 & 220 & 3 & neg & neg & neg \\
\hline & 13 & $F$ & 7 & 160 & 3 & neg & neg & neg \\
\hline & 14 & $F$ & 11 & 120 & 3 & neg & neg & neg \\
\hline & 15 & $M$ & 1 & 130 & 3 & neg & neg & neg \\
\hline & 16 & $F$ & 1 & 110 & 3 & neg & neg & neg \\
\hline & 18 & $F$ & 0.5 & 70 & 3 & neg & neg & neg \\
\hline & 19 & $F$ & 0.5 & 70 & 3 & neg & neg & neg \\
\hline & 20 & $\mathrm{~F}$ & 0.5 & 70 & 3 & neg & neg & neg \\
\hline
\end{tabular}

nt not tested

In this study, no statistically significant haematological differences were found between tigers of group A and B (Table 2). Similarly, haematological and biochemical parameters are usually not modified in L. infantum infected dogs with or without mild localized clinical signs but positive to direct diagnostic methods or presenting low-titre or none anti-Leishmania antibodies [7, 16, 22].

Conversely, a significant protein imbalance including hyperproteinemia, hyperglobulinemia and decreased albumin/globulin ratio were detected in group A (Table

Table 2 Mean and median (in brackets) values of complete blood count (CBC) parameters obtained from group A (L. infantumpositive tigers) and B (L. infantum-negative tigers)

\begin{tabular}{lllll}
\hline CBC parameters & Reference values $(\mathrm{ZIMS})$ & Group A $(n=9)$ & Group B $(n=11)$ & $p$ value \\
\hline RBC $\left(\times 10^{6} / \mu \mathrm{L}\right)$ & $6.98(7.01)$ & $7.5(7.7)$ & $7.3(7.3)$ & $13.4(13.5)$ \\
HGB $(\mathrm{g} / \mathrm{dL})$ & $13.3(13.5)$ & $13(13)$ & $39.8(39.8)$ & 0.49 \\
$\mathrm{HCT}(\%)$ & $40.1(40.2)$ & $39.3(40.1)$ & $298.3(297)$ & 0.64 \\
$\mathrm{PLT}$ & $238(229)$ & $322.6(322)$ & $12.9(13.2)$ & 0.19 \\
WBC $\left(\times 10^{3} / \mu \mathrm{L}\right)$ & $10.4(10)$ & $14.6(13.7)$ & $82.5(0)$ & 0.42 \\
Band neutrophils $(/ \mu \mathrm{L})$ & & $58.1(0)$ & $10,859.2(10,693.5)^{\mathrm{a}}$ & 0.88 \\
Segmented neutrophils $(/ \mu \mathrm{L})$ & $7490(7330)$ & $12,214.2(11371)$ & $1440.7(1610)^{\mathrm{a}}$ & 0.50 \\
Lymphocytes $(/ \mu \mathrm{L})$ & $1450(1340)$ & $1549.4(1344)$ & $335.4(312)^{\mathrm{a}}$ & 0.69 \\
Monocytes $(/ \mu \mathrm{L})$ & $301(260)$ & $350.4(322)$ & $166(167)^{\mathrm{a}}$ & 0.60 \\
Eosinophils $(/ \mu \mathrm{L})$ & $191(160)$ & $427.8(350)$ & & 0.09 \\
\hline
\end{tabular}

Significant $p$ values are printed in bold 
Table 3 Mean and median (in brackets) values of biochemical, serum protein electrophoresis and urinalysis values obtained from group A (L. infantum-positive tigers) and B (L. infantum-negative tigers)

\begin{tabular}{|c|c|c|c|c|}
\hline Parameters & Reference values (ZIMS) & Group A $(n=9)$ & Group B $(n=11)$ & $p$ value \\
\hline \multicolumn{5}{|l|}{ Biochemical profile } \\
\hline CK (IU/L) & 242 (199) & $258.6(200)$ & $160.2(153)$ & 0.29 \\
\hline AST (IU/L) & $31(26)$ & $27.7(23)$ & $25(22)$ & 0.37 \\
\hline $\mathrm{ALT}(\mathrm{IU} / \mathrm{L})$ & $73(62)$ & $47.2(43)$ & $46.1(47)$ & 0.66 \\
\hline ALP (IU/L) & $27(20)$ & $19.3(13)$ & $114.3(40)$ & 0.07 \\
\hline GGT (IU/L) & $2(1)$ & $0.5(0.7)$ & $0.7(0.7)$ & 0.52 \\
\hline Total bilirubin (mg/dL) & $0.2(0.1)$ & $0.2(0.2)$ & $0.1(0.1)$ & 0.08 \\
\hline Glucose (mg/dL) & $144(135)$ & $119.1(125)$ & $121.6(124)$ & 0.86 \\
\hline BUN (mg/dL) & $31.4(30)$ & $64.3(63)$ & $60.9(61)$ & 0.42 \\
\hline Creatinine $(\mathrm{mg} / \mathrm{dL})$ & $2.5(2.5)$ & $2.5(2.5)$ & $2.2(2.4)$ & 0.41 \\
\hline Serum iron ( $\mu \mathrm{g} / \mathrm{dL})$ & $99(92)$ & $68.6(68)$ & $80(83)$ & 0.22 \\
\hline $\mathrm{TIBC}(\mu \mathrm{g} / \mathrm{dL})$ & $306(293)$ & $251.1(243.5)$ & $285.5(280)$ & 0.04 \\
\hline UIBC ( $\mu \mathrm{g} / \mathrm{dL})$ & & $181.7(185)$ & $205.5(219)$ & 0.13 \\
\hline Total proteins (g/dL) & $7.1(7.1)$ & $8.7(8.7)$ & $7.5(7.3)$ & 0.003 \\
\hline Albumin (g/dL) & $3.7(3.7)$ & $3.2(3.3)$ & $3.3(3.4)$ & 0.40 \\
\hline Globulins (g/dL) & $3.5(3.4)$ & $5.5(5.9)$ & $4.1(4.2)$ & 0.01 \\
\hline Albumin/Globulins ratio (g/dL) & $1.1(1.1)$ & $0.6(0.5)$ & $0.8(0.8)$ & 0.05 \\
\hline HPT (mg/dL) & & $155.5(171.9)$ & $92.5(85.2)$ & 0.02 \\
\hline CRP $(\mathrm{mg} / \mathrm{dL})$ & & $7.1(5.9)$ & $9.3(8.5)$ & 0.22 \\
\hline $\mathrm{SAA}(\mu \mathrm{g} / \mathrm{mL})$ & & $145.3(24.4)$ & $42.8(1.2)$ & 0.20 \\
\hline \multicolumn{5}{|l|}{ Serum protein electrophoresis } \\
\hline Total proteins (g/dL) & $7.1(7.1)$ & $8.7(8.7)$ & $7.6(7.4)$ & 0.01 \\
\hline Albumin (g/dL) & $3.66(3.7)$ & $3.5(3.5)$ & $3.7(3.7)$ & 0.34 \\
\hline a-1 globulins (g/dL) & $0.38(0.3)$ & $0.2(0.3)$ & $0.3(0.3)$ & 0.09 \\
\hline a-2 globulins (g/dL) & $0.53(0.47)$ & $1.0(1.0)$ & $0.7(0.7)$ & 0.07 \\
\hline$\beta$ globulins (g/dL) & $0.81(0.72)$ & $1.0(1.0)$ & $1.0(1.0)$ & 0.72 \\
\hline Y globulins (g/dL) & $1.57(1.61)$ & $2.9(3.2)$ & $1.9(1.9)$ & 0.03 \\
\hline Albumin/Globulins ratio & & $0.8(0.6)$ & $1.1(0.9)$ & 0.08 \\
\hline \multicolumn{5}{|l|}{ Urinanalysis } \\
\hline PS & $1034(1035)$ & $1056.8(1057)^{a}$ & $1054(1055.5)^{b}$ & 0.68 \\
\hline UP/C & $0(0)$ & $0.2(0.2)^{a}$ & $0.2(0.1)^{b}$ & 0.31 \\
\hline
\end{tabular}

Significant $p$ values are printed in bold

ZIMS Species 360 (Zoological Information Management System 2017)

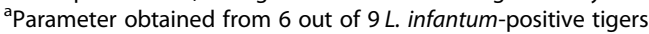

${ }^{\mathrm{b}}$ Parameter obtained from 6 out of $11 \mathrm{~L}$. infantum-negative tigers

3). These abnormalities in the biochemistry panel can appear early during the onset of VL [15] being associated with disease progression [16] and represent a typical finding in CanL, as also described in cases of cats with FeL $[15,17,18]$. In addition, no difference in the levels of albumin in the group A compared to group B was found, similarly to cats where hypoalbuminemia has been only occasionally detected [17].

The biochemical alterations were partially confirmed by the SPE results revealing a significant increase in the total protein value $(p=0.01)$ and a hypergammaglobulinemia $(p=0.03)$ but an unmodified albumin/globulin ratio in group A (Table 3). Furthermore, even though a significant increase of $\alpha-2$ globulins in group A $(1.0 \mathrm{~g} / \mathrm{dL})$ compared to group $B(0.7 \mathrm{~g} / \mathrm{dL})$ was not found, the value of this globulin in $L$. infantum-positive animals was moderately increased referred to the ZIMS reference parameter for tigers $(0.53 \mathrm{~g} /$ dL) (Table 3). $\alpha-2$ globulins includes most of the positive APP, as haptoglobin, which are powerful indicators of inflammation during CanL [15]. Therefore, the lightly 
increased of $\alpha-2$ globulins in group A can be explained by the significantly increase of the haptoglobin $(p=0.02)$ detected in L. infantum-positive tigers (Table 3).

The presence of renal disease in group A can be excluded considering the absence of alteration in renal function markers as the serum concentration of creatinine and BUN, the urine specific gravity and the urine protein/creatinine ratio (Table 3). These markers are useful to suspect severe/very severe CanL with renal involvement [16] causing a chronic kidney disease (CKD) that is a well-recognized condition potentially fatal for dogs affected by CanL [15]. Though renal failure in association with FeL has been described, the exact role of $L$. infantum infection in the development of multiorgan injury with renal impairment has to be confirmed [17]. Therefore, considering the lack of information on leishmaniasis in tigers, further studies are necessary to draw any conclusion on the potential non-involvement of the kidney in this new species.

The clinicopathological picture of L. infantum-infected tigers emerging from the present study is mainly characterized by a subclinical condition and few proteinrelated laboratory abnormalities, which highly supports the hypothesis on the potential role of tigers as alternative local reservoir of L. infantum. Similarly, this picture has been suggested also for cats, which presumably act as reservoir hosts at least in endemic areas of zoonotic VL [12-14].

Although laboratory abnormalities are usually aspecific in animals with VL [15], they can represent a wake-up call for veterinarians working with tigers in zoological parks where routine screening for VBDs as leishmaniasis is not frequent. Furthermore, performing laboratory tests could be essential in L. infantum-positive tigers which live in an endemic area, thus being at risk of infection $(n=9 / 20,45 \%)$. However, the potential limitation of the study consists of the impossibility of carrying out an indepth clinical examination that would allow all clinical signs related to VL (e.g., splenomegaly) to be properly evaluated. Another limit of the study could be represented by the absence of information on potential other diseases affecting tigers which can influence the laboratory parameters. Finally, the available haematological and biochemical reference values in tigers are limited and obtained from a small population size not properly divided considering age, sex and sampling season [23].

\section{Conclusions}

In this study tigers infected with $L$. infantum have shown to be mainly asymptomatic considering the clinical pictures classically observed in CanL and FeL. The complete absence of clinical signs may lead veterinarians to overlook leishmaniasis in animals kept in captivity where the health condition of the animals is usually checked by periodical visual examinations. Therefore, diagnostic and screening test as serology should be part of routinely surveillance programs to be performed on tigers in zoological gardens located in endemic areas. Though only few protein-related laboratory abnormalities have been detected in infected animals, they can provide essential diagnostic clues for identification of $L$. infantum infection in tigers. This may play an important role in the conservation of this endangered species of wild felids as well as in reducing the risk of zoonotic transmission in heavily frequented environment as zoos.

\section{Methods}

\section{Study area and animals' enrolment}

Twenty tigers housed at a Safari Park (Apulia region, Brindisi Province, southern Italy) $\left(40^{\circ} 50^{\prime} \mathrm{N}, 17^{\circ} 20^{\prime} \mathrm{E}\right)$ were involved in the study. Those animals have been previously enrolled in an epidemiological investigation aimed at evaluate the prevalence of $L$. infantum infection after the identification of an index case in the tiger population, using both serological and molecular methods. Nine (45\%) out of 20 tigers were positive to $L$. infantum by immunofluorescence antibody test (IFAT) $(9 / 20,45 \%)$ and/or by real time-PCR $(5 / 20,25 \%)$, being five of them $(5 / 20,25 \%)$ positive by both methods.

Out of 9 serologically positive tigers, three animals presented an antibody titre of 1:40, four of $1: 80$, one of 1:160 and one of 1:640 each, respectively. Therefore, according to these results [24] in the overall tiger population two groups were set up: $L$. infantum-positive animals $(n=9$; group $\mathrm{A})$ and $L$. infantum-negative animals $(n=11$; group $\mathrm{B})$.

\section{Clinical evaluation}

Food and water were withheld for $12 \mathrm{~h}$ prior to anaesthesia. Upon arrival at the zoological park, each animal was anesthetised, via remote injection, with a combination of $250 \mathrm{mg}$ of zolazepam/tiletamine (Zoletil 50/50, Virbac) plus $3 \mathrm{mg}$ of detomidine (Mesden $10 \mathrm{mg} / \mathrm{ml}$, FM Italia) [25]. Then, a complete physical exam was performed, and for each animal body condition score was assessed [26]. The clinical visit included a whole-body visual examination for cutaneous lesions and lymph nodes evaluation. After verifying sex and reproductive status, external genitalia and perineum were inspected. Mucous membrane colour and moisture were observed. Other visual observations included evaluation for normal breathing patterns and rate.

At the end of the procedures (i.e. $30-45 \mathrm{~min}$ after darting), immobilization of the tigers was reversed with intramuscular administration of $15 \mathrm{mg}$ of atipamezole (Antisedan 0.5\%, Pfizer, Milan, Italy) [25]. After recovery (i.e. $\simeq 10 \mathrm{~min}$ ), each tiger was closely monitored for $8 \mathrm{~h}$ and, thereafter, reintroduced into the colony of the zoo. 


\section{Blood samples and analysis}

Blood (12 mL) was collected from the cephalic vein and placed in tubes with EDTA $(2 \mathrm{~mL})$ to perform routine haematology, and in plain tubes $(10 \mathrm{~mL})$ to obtain serum. Serum was obtained within $4 \mathrm{~h}$ from collection, by centrifugation ( $15 \mathrm{~min}$ at $1500 \mathrm{x} \mathrm{g}$ ).

Results from complete blood count (CBC) (Siemens, ADVIA 2120), serum biochemical analysis (Beckman Coulter, Clinical Chemistry Analyzer AU680) and electrophoresis (SEBIA, Capillarys 2 Flex Piercing) were achieved with the same methods in all samples.

\section{Urine collection and urinalysis}

All urine samples were collected by catheterization, using a $20 \mathrm{~mL}$ syringe connected to a $14 \mathrm{Ch}$ catheter. Urine samples were placed in $10 \mathrm{~mL}$, sterile, evacuated collection tubes, stored at room temperature (approximately $20^{\circ} \mathrm{C}\left[676^{\circ} \mathrm{F}\right]$ ), and analysed within $4 \mathrm{~h}$ from collection. Urine sediment was obtained by centrifugation $(10 \mathrm{~min}$ at $900 \mathrm{x} \mathrm{g})$ of $5 \mathrm{~mL}$ of urine, followed by removal of $4.5 \mathrm{~mL}$ of supernatant, and resuspension of the remaining $0.5 \mathrm{~mL}$ of urine. A sample of $12 \mu \mathrm{L}$ of the resuspended urine was microscopically assessed. Red blood cells and white blood cells were expressed as mean number of cells $/ 10 \mathrm{hpf}(40 \times$ magnification $)$. Urine sediment with bacteriuria, and/or $>5$ red blood cells or white blood cells/hpf, was considered indicative of active inflammation and excluded from the UPC ratio evaluation. The supernatant was transferred into separate tubes to determine UPC ratio. To calculate the UPC ratio, protein concentration $(\mathrm{mg} / \mathrm{dL})$ was measured with pyrogallol red, and creatinine $(\mathrm{mg} / \mathrm{dL})$ was measured using the Jaffé method on undiluted urine supernatant that was thawed before analysis. Results were achieved with the same method in all samples (Beckman Coulter, Clinical Chemistry Analyzer AU680).

\section{Data analysis}

The Kolmogorov-Smirnov test was used to assess the normality of the data. Statistical differences between group A and group B were tested for significance by Student's t-test for normally distributed data and with the Mann-Whitney test for not normally distributed data. A value of $P<0.05$ was considered statistically significant. The statistical analyses were performed using GraphPad Prism version 8.0.0 (GraphPad Software, San Diego California, USA).

\footnotetext{
Abbreviations

ALP: Alkaline phosphatase; ALT: Alanine aminotransferase; AST: Aspartate aminotransferase; BUN: Blood urea nitrogen; CanL: Canine leishmaniasis; CBC: Complete blood count; CK: Creatine kinase; CRP: C-reactive protein; EDTA: Ethylenediamine tetraacetic acid; FeL: Feline leishmaniasis; GGT: Gamma glutamyltransferase; HCT: Hematocrit; HGB: Hemoglobin; HPT: Haptoglobin; IFAT: Immunofluorescence antibody test; PLT: Platelet; RBC: Red blood cell; SAA: Serum amyloid A; SPE: Serum protein electrophoresis; TIBC: Total Iron Binding Capacity; UIBC: Unsaturated iron
}

binding capacity; UP/C: Urine protein creatinine ratio; VL: Visceral leishmaniasis; WBC: White blood cell

\section{Acknowledgements}

The authors would like to thank the zoo employees for their valid support during field activities.

\section{Authors' contributions}

AZ and DO planned the study; MAC wrote the paper and performed the statistical analysis; MAC, RI, PL, JAMR and DO were involved in the acquisition of the field samples; FA and GP performed the histopathological evaluation; RI, PL, GP, FA, JAMR, DO and AZ revised the manuscript. All authors have read and approved the manuscript.

\section{Funding}

This research did not receive any specific grant from funding agencies in the public, commercial, or not-for-profit sectors.

\section{Availability of data and materials}

Data sets generated from this study are available upon request to the corresponding author.

\section{Ethics approval and consent to participate}

Written informed consent was obtained from the owners of the tigers (Zoo Safari di Fasano, Brindisi, Italy) to collect samples from the animals.

Furthermore, the protocol of this study has been approved by the Ethics Committee of the Department of Veterinary Medicine, University of Bari, Italy (authorization Prot. Uniba 9/19).

\section{Consent for publication}

Not applicable.

\section{Competing interests}

The authors declare no competing interests for the submission of this article.

\section{Author details}

${ }^{1}$ Department of Veterinary Medicine, University of Bari, 70010 Valenzano, Italy. '2Zoo Safari di Fasano, Fasano, 72015 Brindisi, Italy. ${ }^{3}$ Department of Veterinary Science, University of Pisa, Pisa, 56124 Pisa, Italy. ${ }^{4}$ Faculty of Veterinary Sciences, Bu-Ali Sina University, Hamedan, Iran.

Received: 28 January 2020 Accepted: 8 June 2020

Published online: 22 June 2020

\section{References}

1. Ribeiro RR, Michalick MSM, da Silva ME, Dos Santos CCP, Frézard FJG, da Silva SM. Canine Leishmaniasis: an overview of the current status and strategies for control. Biomed Res Int. 2018;2018:3296893. https://doi.org/10. 1155/2018/3296893.

2. World Health O. Leishmaniasis. 2018. Available from: http://www.who.int/ mediacentre/factsheets/fs375/en/.

3. Vilas VJ, Maia-Elkhoury AN, Yadon ZE, Cosivi O, Sanchez-Vazquez MJ. Visceral leishmaniasis: a one health approach. Vet Rec. 2014;175:42-4. https://doi. org/10.1136/vr.g4378.

4. Dantas-Torres F, Solano-Gallego L, Baneth G, Ribeiro VM, de Paiva-Cavalcanti M, Otranto D. Canine leishmaniosis in the old and new worlds: unveiled similarities and differences. Trends Parasitol. 2012;28:531-8. https://doi.org/ 10.1016/j.pt.2012.08.007.

5. Solano-Gallego L, Miró G, Koutinas A, Cardoso L, Pennisi MG, Ferrer L, Bourdeau P, Oliva G, Baneth G, The LeishVet Group. LeishVet guidelines for the practical management of Canine Leishmaniosis. Parasit Vectors. 2011;4: 86. https://doi.org/10.1186/1756-3305-4-86.

6. Hosein S, Blake DP, Solano-Gallego L. Insights on adaptive and innate immunity in canine leishmaniosis. Parasitology. 2017;144:95-115. https://doi. org/10.1017/S003118201600055X.

7. Paltrinieri S, Solano-Gallego L, Fondati A, Lubas G, Gradoni L, Castagnaro M, Crotti A, Maroli M, Oliva G, Roura X, Zatelli A, Zini E, Canine Leishmaniasis Working Group, Italian Society of Veterinarians of Companion Animals. Guidelines for diagnosis and clinical classification of leishmaniasis in dogs. J Am Vet Med Assoc. 2010;236:1184-91. https://doi.org/10.2460/javma.236.11.1184. 
8. Meléndez-Lazo A, Ordeix L, Planellas M, Pastor J, Solano-Gallego L. Clinicopathological findings in sick dogs naturally infected with Leishmania infantum: comparison of five different clinical classification systems. Res Vet Sci. 2018:117:18-27. https://doi.org/10.1016/.rvsc.2017.10.011.

9. Roque AL, Jansen AM. Wild and synanthropic reservoirs of Leishmania species in the Americas. Int J Parasitol Parasites Wildlife. 2014;3:251-62. https://doi.org/10.1016/j.jppaw.2014.08.004.

10. Millán J, Ferroglio E, Solano-Gallego L. Role of wildlife in the epidemiology of Leishmania infantum infection in Europe. Parasitol Res. 2014;113:2005-14.

11. Otranto D, Cantacessi C, Pfeffer M, Dantas-Torres F, Brianti E, Deplazes P, Genchi C, Guberti V, Capelli G. The role of wild canids and felids in spreading parasites to dogs and cats in Europe. Part I: Protozoa and tickborne agents. Vet Parasitol. 2015;213:12-23. https://doi.org/10.1016/j.vetpar. 2015.04.022

12. Asfaram S, Fakhar M, Teshnizi SH. Is the cat an important reservoir host for visceral leishmaniasis? A systematic review with meta-analysis. J Venom Anim Toxins Incl Trop Dis. 2019;25:e20190012. https://doi.org/10.1590/16789199-JVATITD-2019-0012.

13. latta R, Furlanello T, Colella V, Tarallo VD, Latrofa MS, Brianti E, Trerotoli P, Decaro N, Lorusso E, Schunack B, Mirò G, Dantas-Torres F, Otranto D. A nationwide survey of Leishmania infantum infection in cats and associated risk factors in Italy. PLoS Negl Trop Dis. 2019:13:e0007594.

14. Pennisi MG, Persichetti MF. Feline leishmaniosis: is the cat a small dog? Vet Parasitol. 2018;251:131-7. https://doi.org/10.1016/j.vetpar.2018.01.012.

15. Paltrinieri S, Gradoni L, Roura X, Zatelli A, Zini E. Laboratory tests for diagnosing and monitoring canine leishmaniasis. Vet Clin Pathol. 2016;45: 552-78. https://doi.org/10.1111/vcp.12413.

16. Maia C, Campino L. Biomarkers associated with Leishmania infantum exposure, infection, and disease in dogs. Front Cell Infect Microbiol. 2018;8: 302. https://doi.org/10.3389/fcimb.2018.00302.

17. Pennisi MG, Cardoso L, Baneth G, Bourdeau P, Koutinas A, Miró G, Oliva G, Solano-Gallego L. LeishVet update and recommendations on feline leishmaniosis. Parasit Vectors. 2015;8:1-18. https://doi.org/10.1186/s13071015-0909-z.

18. Soares CS, Duarte SC, Sousa SR. What do we know about feline leishmaniosis? J Feline Med Surg. 2016;18:435-42. https://doi.org/10.1177/ $1098612 \times 15589358$

19. de Oliveira AR, de Carvalho TF, Arenales A, Tinoco HP, Coelho CM, Costa MELT, Paixão TA, Caixeta EA, Pinheiro GRG, Santos RL. Mandibular squamous cell carcinoma in a captive siberian tiger (Panthera tigris altaica). Brazilian J Vet Pathol. 2018;11:97-101.

20. Tolentino N, Pinheiro GRG, Ottino J, de Oliveira AR, Coelho CM, Tinoco HP, Fujiwara RT, Santos RL, Ribeiro VM. Serological evidence of Leishmania infection by employing ELISA and rapid tests in captive felids and canids in Brazil. Vet Parasitol Reg Stud Reports. 2019;17:100308. https://doi.org/10. 1016/j.vprsr.2019.100308.

21. The IUCN Red List of Threatened Species. Version 2015.2. 2015. Available from: https://www.iucnredlist.org/species/15955/50659951.

22. Solano-Gallego L, Koutinas A, Miró G, Cardoso L, Pennisi MG, Ferrer L, Bourdeau P, Oliva G, Baneth G. Directions for the diagnosis, clinical staging, treatment and prevention of canine leishmaniosis. Vet Parasitol. 2009;165:118. https://doi.org/10.1016/j.vetpar.2009.05.022.

23. Padmanath K, Dash D, Behera PC, Sahoo N, Sahoo G, Subramanian S, Bisoi PC. Biochemical reference values of captive Royal Bengal tigers (Panthera tigris tigris) in Orissa, India. Int J Adv Res Biol Sci. 2015;2:274-8.

24. latta R, Zatelli A, Laricchiuta P, Legrottaglie M, Modry D, Dantas-Torres F, Otranto D. Leishmania infantum in tigers and sand flies from a leishmaniasis-endemic area, Southern Italy. Emerg Infect Dis. 2020;26(6): 1311-4. https://doi.org/10.3201/eid2606.191668.

25. Laricchiuta P, De Monte V, Campolo M, Grano F, Crovace A, Staffieri F. Immobilization of captive tigers (Panthera tigris) with a combination of tiletamine, zolazepam, and detomidine. Zoo Biol. 2015;34:40-5.

26. AZA Tiger Species Survival Plan ${ }^{\oplus}$. Tiger care manual. Silver Spring: Association of Zoos and Aquariums; 2016.

\section{Publisher's Note}

Springer Nature remains neutral with regard to jurisdictional claims in published maps and institutional affiliations.

\section{Ready to submit your research? Choose BMC and benefit from:}

- fast, convenient online submission

- thorough peer review by experienced researchers in your field

- rapid publication on acceptance

- support for research data, including large and complex data types

- gold Open Access which fosters wider collaboration and increased citations

- maximum visibility for your research: over $100 \mathrm{M}$ website views per year

At $\mathrm{BMC}$, research is always in progress.

Learn more biomedcentral.com/submissions 